\title{
Does Gastric Surgery (Such as Bariatric Surgery) Impact the Risk of Intestinal Inflammation?
}

\author{
Daniel Gero Christian A. Gutschow Marco Bueter \\ Department of Visceral and Transplant Surgery, University Hospital Zurich, Zurich, Switzerland
}

\section{Key Words}

Gastric bypass $\cdot$ Inflammatory bowel disease $\cdot$ Morbid obesity · Roux-en-Y gastric bypass · Sleeve gastrectomy

\begin{abstract}
Background: The prevalence of morbid obesity and inflammatory bowel disease (IBD) is on the rise in association with a Western lifestyle. Both conditions are characterized by chronic inflammation. Bariatric surgery (BS) is a recommended and widely used approach to address severe obesity and its related comorbidities. Roux-en-Y gastric bypass (RYGBP) and sleeve gastrectomy (SG) are the most frequently performed procedures worldwide. Evidence is scarce on outcomes of BS in IBD patients. Summary: Systemic and adipose-tissue inflammation seems to decrease following BS. Different studies observed decreased serum levels of inflammatory markers (CRP, IL-6, MCP-1, and TNF- $a$ ) along with a reduction of insulin resistance both after RYGBP and SG. Several authors documented postbariatric improvement of concomitant chronic inflammatory diseases (rheumatoid arthritis, systemic lupus erythematosus, gout, and psoriasis). There are only few retrospective case series on outcomes of BS in IBD patients. These studies reported safety and feasibility of $\mathrm{BS}$ and improvement in IBD status, manifested by prolonged disease remission and decreased use of pharmacotherapy. Weight loss outcomes were excellent and similar to those of
\end{abstract}

non-IBD patients. The preferred surgical approach for morbidly obese IBD patients is SG in order to avoid potential drawbacks of RYGBP, such as malabsorption, intestinal manipulation, and augmentation of technical difficulties for future IBD surgery. Seven cases of newly diagnosed IBD after BS have been reported, which are more likely to result from postoperative intestinal microbial dysbiosis than from directly induced inflammation. Key Messages: This review summarizes the outcomes of BS in IBD patients. SG is the preferable technique for morbidly obese IBD patients, who have potentially a double benefit from BS: weight loss and IBD remission. Further research is necessary to clarify the common pathophysiology of chronic inflammation in morbid obesity and in IBD. Postbariatric changes in gut microbiota should also be assessed to understand whether they promote IBD development or not.

(c) 2016 S. Karger AG, Basel

\section{Introduction}

Both metabolic syndrome (MS) and inflammatory bowel disease (IBD) are characterized by chronic inflammation and share common features in their pathology [1]. MS triggers inflammatory signals, and vice versa, IBD generates several metabolic changes. The prevalence of these conditions is on the rise in association with the pop-

\section{KARGER}

E-Mail karger@karger.com

www.karger.com/iid (c) 2016 S. Karger AG, Base

2296-9403/16/0013-0129\$39.50/0
Prof. Dr. med. Marco Bueter, PhD

Department of Visceral and Transplant Surgery, University Hospital Zurich Rämistrasse 100

CH-8091 Zurich (Switzerland)

E-Mail marco.bueter@usz.ch 
ularity of a Western lifestyle $[2,3]$. The clinical development of IBD starts with a defective mucosa facilitating the intestinal bacteria to cross the mucosal barrier and to induce an immune response mediated by proinflammatory cytokines along with diminished levels of immunosuppressive cytokines; consequently, chronic inflammation occurs [4]. In obesity, chronic inflammation originates from proinflammatory cytokines and adipokines such as tumor necrosis factor- $\alpha$ (TNF- $\alpha$ ), interleukin-6 (IL-6), and monocyte chemoattractant protein (MCP-1) secreted by adipocytes or by macrophages and lymphocytes that infiltrate the mesenteric fat, which is overexpressed in patients with active IBD [5].

Obesity affects over 640 million people worldwide, and if the present trends continue, the global obesity prevalence will reach $20 \%$ by 2025 [6]. Bariatric surgery (BS) is superior to lifestyle modifications alone (diet, sport, and medical treatment) in achieving body weight loss, and it is also effective in the treatment of obesityrelated comorbidities, especially in type 2 diabetes mellitus (T2DM) $[7,8]$. Currently, the most frequently performed BS procedures are the Roux-en-Y gastric bypass (RYGBP) and sleeve gastrectomy (SG) [9].

The incidence of IBD, defined as either Crohn's disease (CD) or ulcerative colitis (UC), is also continuously increasing along with a higher socioeconomic status which has been recently identified as an independent risk factor [10]. Obesity and overweight have become commonplace in adult IBD patients, with a prevalence of 32 $52 \%$ in different European studies $[11,12]$. Obesity is more frequently associated with CD than with UC [11].

It is the aim of this review to assess the impact of BS on systemic inflammation and discuss the outcomes of bariatric procedures in IBD patients against the background of the available evidence in the literature.

\section{Common Bariatric Techniques and Outcome}

RYGBP and SG are recommended and widely used in the treatment of severe obesity and its related comorbidities [13]. RYGBP consists of the creation of a small proximal gastric pouch (approximately $20 \mathrm{ml}$ ), which is connected to a jejunal (alimentary) limb with a length of $100-150 \mathrm{~cm}$. A 50 - to $80-\mathrm{cm}$ biliopancreatic limb is anastomosed to the alimentary limb, and the small bowel distal to this anastomosis is called the common limb, which harbors the majority of intestinal absorption. In the long term, these anatomic changes in the digestive tract may lead to gastrointestinal complications (nausea, vomiting, diarrhea, and dumping syndrome) and nutritional deficiencies (iron, vitamin $A$, vitamin $B_{1}$, vitamin $B_{12}$, vitamin $\mathrm{D}$, folic acid, and zinc) or dehydration [14]. A recent meta-analysis demonstrated an association between RYGBP and an increased risk of kidney stones, contrarily to other BS procedures such as gastric banding or SG, which may decrease kidney stone risk [15].

During SG, the stomach is tubularized over a calibration bougie, and approximately $80 \%$ of its volume is resected parallel to the greater curvature. Like the RYGBP, the SG decreases gastric reservoir function and activates hormonal mechanisms such as increased GLP-1 hormone and decreased ghrelin [16]. The most frequent medical complication is gastroesophageal reflux disease, which might be promoted by both an increased postoperative gastroesophageal pressure gradient and the destruction of the angle of His during gastric sleeve formation. Further medical complications include recurrent aspiration pneumonia, dumping syndrome, and ketoacidosis [17]. Symptomatic cholelithiasis is rare $(<5 \%)$; however, it was reported to be more likely to occur after SG than after RYGBP [18].

In experienced centers, both RYGBP and SG have an excellent safety profile with low perioperative morbidity and close-to-zero mortality [19]. Nevertheless, both procedures can lead to various late medical complications, as mentioned above. A meta-analysis found a similar rate of minor and major complications from 6 months to 3 years following the two procedures [17].

\section{BS and Inflammation}

To the best of our knowledge, there is no evidence indicating that BS may promote intestinal inflammation. On the contrary, systemic and adipose-tissue inflammation seems to decrease following bariatric procedures both at the biochemical and at the clinical level. These changes supposedly promote risk reduction in obesityassociated comorbid conditions including T2DM, cardiovascular diseases, infections, and cancer [20-23].

Viana et al. [20] demonstrated a significant decrease in systemic inflammatory cytokines (IL- 6 and TNF- $\alpha$ ) 1 year after RYGBP and SG. Sams et al. [21] found a significant and rapid increase in subcutaneous adipose antiinflammatory cytokines (e.g. adiponectin) by enzymelinked immunosorbent assay already 2 weeks following RYGBP, potentially contributing to systemic inflammation reduction. In the same study, insulin resistance was also found to be reduced, which could have an important 
role in the amelioration of T2DM and, thus, in the reduction of long-term mortality. A study in adolescents undergoing RYGBP and SG also showed that the levels of IL-6, TNF- $\alpha$, MCP-1, oxidized low-density lipoprotein cholesterol, and leptin significantly decreased while adiponectin increased, indicating a marked decrease in systemic inflammation and oxidative stress [22]. Consistently with the previously cited studies on RYGBP, Brethauer et al. [23] demonstrated a decrease in inflammatory cytokines and also a decrease in the levels of C-reactive protein, fasting insulin, and fibrinogen, along with an amelioration in arterial endothelial function, a further surrogate marker of cardiovascular risk reduction after RYGBP.

The impact of BS on systemic inflammation can also be observed by the postoperative improvement in concomitant chronic inflammatory diseases. Sparks et al. [24] reported a decrease in rheumatoid arthritis disease activity enabling lower medication use following SG. Romero-Talamás et al. [25] observed a decrease in psoriasis in $40 \%$ of patients following RYGBP and found that the remission correlated with the extent of excess weight loss. Yildiz [26] reported remission of psoriasis already 1 month after SG in 2 patients. Other studies showed improvement in gout (decreased uric acid levels 1 year after BS) and decreased immunosuppression medication requirements for systemic lupus erythematosus following BS $[27,28]$.

\section{Abdominal Surgery in IBD Patients}

Surgical management of IBD is complex and challenging [29]. In CD, the goal of surgery is to improve quality of life. It should be reserved for patients who develop medically unresponsive strictures, abscesses, or fistulas. In UC, proctocolectomy and ileo-anal pouch reservoir have become the preferred surgical management for advanced disease states. Surgery is required in $30-40 \%$ of patients with $\mathrm{CD}$ and $20-30 \%$ of patients with UC at some point during their lifetime [30]. Laparoscopy is the preferred approach for IBD operations due to faster intestinal function recovery, better cosmesis, less overall postoperative complications, and shorter inpatient stay [31]. Anatomic changes induced by obesity increase the technical complexity of these procedures, and obesity-related comorbidities might increase the risk of postoperative complications [32]. The American College of Surgeons National Surgical Quality Improvement Program Database showed that an increasing body mass index (BMI) adversely affected postoperative complications in

Intestinal Inflammation and Bariatric Surgery
CD patients [32]. Nevertheless, a more recent retrospective cohort study found that obesity did not impact intraoperative variables, nor did it worsen postoperative complication rates in IBD patients [33].

\section{Outcomes of BS in IBD Patients}

IBD is a chronic condition with periods of remission and relapse. Accurate assessment of disease progression is based on the combination of clinical signs (weight loss, fatigue, quality and frequency of stools, abdominal discomfort) and endoscopic/histologic evaluation of mucosal healing [34]. Noninvasive methods for evaluating disease activity or predicting mucosal status also exist. A reliable surrogate marker of intestinal inflammation is the fecal calprotectin level, which correlates with IBD disease activity observed by capsule endoscopy [35]. This marker has not been studied after BS; however, the plasmatic calprotectin was measured in one study in non-IBD morbidly obese patients who underwent BS. Nijhuis et al. [36] found a significant decrease in serum calprotectin levels (in 11 out of 15 patients) from a mean of $119.6 \pm 31.5 \mathrm{ng} /$ $\mathrm{ml}$ to a mean of $93.9 \pm 42.7 \mathrm{ng} / \mathrm{ml}(\mathrm{p}<0.001) 2$ years postoperatively, suggesting a state of lower neutrophil activation following BS-induced weight loss. Theoretically, the decreased inflammatory state following BS might favorably impact the evolution of IBD; however, surgically induced malabsorption and abdominal surgery including intestinal manipulation might also adversely impact IBD patients [37-39]. The eventual complications that may be more frequent in IBD include anastomotic leak, fistula, abscess, bowel stricture, and bowel obstruction [40]. Furthermore, without any available evidence, Moum and Jahnsen [41] mention the potential risk of exacerbating intestinal inflammation and the increased risk of smallintestine neoplasia following RYGBP. As chronic steroid use is associated with increased morbidity and mortality after BS [42], operating on IBD patients with immunosuppressive treatment should be preceded by meticulous risk stratification.

The available literature is sparse on the outcomes of BS in IBD patients and is predominantly based on case reports or smaller case series. For example, Keidar et al. [37] presented a series of 9 morbidly obese IBD patients (7 CD and 2 UC) who underwent SG and of $1 \mathrm{CD}$ patient who underwent gastric banding. Despite one staple line leak in a UC patient, the authors found that SG was safe and yielded satisfying weight loss-related results without a higher risk of postoperative complications or an in- 
creased risk of postintervention IBD exacerbation. Furthermore, 3 patients were able to stop their 5-ASA treatment. Colombo et al. [38] reported successful BS procedures in 6 IBD patients with concomitant or deferred IBD surgery: SG in 5 CD and 1 UC and vertical banded gastroplasty in $1 \mathrm{CD}$ patient. The authors observed only one perioperative complication (reoperation for staple line bleeding), effective BMI reduction, and absence of intestinal malabsorption. They concluded that BS in IBD patients offers a double benefit: on top of reducing systemic inflammation, the decrease in BMI reduces the pharmacological volume of distribution to the normal therapeutic range of immunosuppressive therapy. Aminian et al. [39] retrospectively identified $13 \mathrm{UC}$ and $7 \mathrm{CD}$ patients who underwent RYGBP, SG, or gastric banding in a large-volume bariatric center. Several early complications were reported, i.e. dehydration $(\mathrm{n}=5)$, pulmonary embolism $(\mathrm{n}=1)$, and wound infection $(\mathrm{n}=1)$. Late complications occurred as well, i.e. pancreatitis $(n=2)$, ventral hernia $(n=2)$, and marginal ulcer $(n=1)$. Most patients experienced improvement in their IBD status, manifested by prolonged disease remission and decreased use of pharmacotherapy. Weight loss outcomes were excellent and similar to those of non-IBD patients. Lascano et al. [43] described a morbidly obese male UC patient who experienced clinical remission of UC with a reduction in medications following RYGBP. Moum and Jahnsen [41] presented a case of a CD patient who experienced an acute flare 5 weeks following RYGBP with increasing calprotectin levels in her feces. She responded well to high doses of infliximab, and 7 months later, she was in remission and achieved weight loss. An adverse outcome was presented by Tenorio et al. [44] who described the case of a UC patient who presented severe protein malnutrition after biliopancreatic diversion (BPD). Protein malnutrition is a frequent complication after BPD compared to RYGBP or SG, which is why BPD is only performed in low numbers in a few bariatric centers worldwide [45]. It is also not recommended in IBD patients who are already at an increased risk of malabsorption [46].

\section{BS as a Risk Factor for IBD?}

A few reports in the literature suggest that BS may be a potential risk factor for the development of CD. However, our literature review could identify only 6 patients from a total of 3 publications who have developed CD after BS [47-49]. Five patients had RYGBP and one had a jejuno-ileal bypass - a historic weight loss operation that nowadays has been abandoned due to a high incidence of complications [50]. The time from surgery to the diagnosis of CD ranged from 2 months to 10 years. Papakonstantinou et al. [51] reported 1 patient who developed UC and acute stroke 3 months after Mason's vertical banded gastroplasty. Although a causal link between BS and IBD has not been established, Janczewska et al. [48] theorized that changes in the intestinal flora promoted by RYGBP might lead to CD in genetically predisposed patients by triggering chronic intestinal inflammation. In fact, intestinal dysbiosis is a crucial component of CD potentially resulting from a combination of inflammation, antibiotic exposure, and dietary changes [52]. However, BS has also been shown to induce changes in gut microbiota. Palleja et al. [53] found an increased gut microbial diversity and an altered microbial composition already 3 months following RYGBP, and these changes were also present at 1 year. Diarrhea following RYGBP is most likely related to a higher fatty acid content of stools due to decreased fat absorption [54]. Nevertheless, CD might be kept in mind as a differential diagnosis for diarrhea and should be ruled out by endoscopy in postbariatric patients who present further alarming signs, such as abdominal pain and unintentional excess weight loss. In order to assess the real incidence of IBD following BS, Ahn et al. [47] planned to perform a prospective cohort study in the Boston Medical Center.

\section{Recommendations on BS in IBD}

MS and IBD share some common denominators, namely a triggered immune response, adipokine-mediated chronic inflammation, and elevated cardiovascular risk, but underlying mechanisms are not fully understood [55]. There are promising results from previously cited case series to support the beneficial effect of BS on IBD in morbidly obese individuals, at least in selected cases. However, the selection of the optimal bariatric procedure for a morbidly obese patient involves many considerations. As the IBD population is at risk for intestinal malabsorption, enteric fistulas, and bacterial overgrowth, most authors and $87 \%$ of the experts from the Fifth International Consensus Conference on current status of SG recommend the use of SG [37-39, 41, 56]. SG achieves satisfying metabolic results and involves the operation of the stomach only, which is in most of the cases free from IBD [37]. Also, SG presents a valid alternative to offset the arguments in disfavor of RYGBP. 
Gastric bypass might predispose to bacterial overgrowth due to lack of gastric acidity, stasis in the afferent loop, and enterocyte toxicity via free bile acids resulting from microbial bile acid deconjugation after gastric diversion [47]. There is a potential risk of flare-up in patients with small-bowel CD in the operated segment of the small bowel after RYGBP, with an increased risk of stricture, abscesses, and fistulas [29]. As RYGBP alters the smallbowel anatomy, it can become the source of additional technical difficulties at the time of postbariatric IBD surgery, e.g. for the creation of an ileal pouch with a protective ileostomy after coloproctectomy. Also, if later in the patient's life an intestinal resection becomes necessary due to the progression of $\mathrm{CD}$, the common limb length might be shortened promoting malabsorption or mandating reversal of RYGBP anatomy. Therefore, Janczewska et al. [48] suggested that CD should be an absolute contraindication to RYGBP, and morbidly obese patients with a history of diarrhea and/or perianal abscess should be investigated for IBD as part of the standard preoperative workup.

\section{Conclusions}

BS is an effective treatment of morbid obesity and provides a decreased systemic inflammatory state, which results in the amelioration of concomitant chronic inflammatory diseases, a reduced risk of T2DM, cardiovascular disease, and other diseases. The literature is scarce on the impact of bariatric procedures in IBD patients. Based on the available evidence, SG seems to be the preferred bariatric technique for morbidly obese IBD patients in order to avoid intestinal manipulation or malabsorption following RYGBP. Few cases of CD after RYGBP have been reported, which are more likely to result from postoperative intestinal microbial dysbiosis than from directly induced inflammation.

\section{Disclosure Statement}

We have no conflicts of interest or financial ties to declare that are relevant to the subject of this review paper and any of the statements in it.

\section{References}

1 Zietek T, Rath E: Inflammation meets metabolic disease: gut feeling mediated by GLP-1. Front Immunol 2016;7:154.

2 Hossain P, Kawar B, El Nahas M: Obesity and diabetes in the developing world - a growing challenge. N Engl J Med 2007;356:213-215.

3 Ye Y, Pang Z, Chen W, Ju S, Zhou C: The epidemiology and risk factors of inflammatory bowel disease. Int J Clin Exp Med 2015;8: 22529-22542.

4 Manuc TE, Manuc MM, Diculescu MM: Recent insights into the molecular pathogenesis of Crohn's disease: a review of emerging therapeutic targets. Clin Exp Gastroenterol 2016; 9:59-70.

5 Ouchi N, Parker JL, Lugus JJ, Walsh K: Adipokines in inflammation and metabolic disease. Nat Rev Immunol 2011;11:85-97.

-6 NCD Risk Factor Collaboration (NCD-RisC): Trends in adult body-mass index in 200 countries from 1975 to 2014: a pooled analysis of 1698 population-based measurement studies with 19.2 million participants. Lancet 2016; 387:1377-1396.

7 Mingrone G, Panunzi S, De Gaetano A, Guidone C, Iaconelli A, Leccesi L, Nanni G, Pomp A, Castagneto M, Ghirlanda G, Rubino F: Bariatric surgery versus conventional medical therapy for type 2 diabetes. N Engl J Med 2012;366:1577-1585.
8 Schauer PR, Bhatt DL, Kirwan JP, Wolski K, Brethauer SA, Navaneethan SD, Aminian A, Pothier CE, Kim ES, Nissen SE, Kashyap SR; STAMPEDE Investigators: Bariatric surgery versus intensive medical therapy for diabetes 3-year outcomes. N Engl J Med 2014;370:20022013.

-9 Khan S, Rock K, Baskara A, Qu W, Nazzal M, Ortiz J: Trends in bariatric surgery from 2008 to 2012. Am J Surg 2016;211:1041-1046.

10 Levi Z, Shamiss A, Fraser GM, Furman M, Derazne E, Tzur D, Gordon B, Welinsky S, Gingold Belfer R, Afek A: The increasing prevalence of inflammatory bowel diseases among Jewish adolescents and the sociodemographic factors associated with diagnosis. Inflamm Bowel Dis 2013;19:1867-1871.

-11 Steed H, Walsh S, Reynolds N: A brief report of the epidemiology of obesity in the inflammatory bowel disease population of Tayside, Scotland. Obes Facts 2009;2:370-372.

12 Blain A, Cattan S, Beaugerie L, Carbonnel F, Gendre JP, Cosnes J: Crohn's disease clinical course and severity in obese patients. Clin Nutr 2002;21:51-57.

13 Caravatto PP, Petry T, Cohen R: Changing guidelines for metabolic surgery: now it's the time! Curr Atheroscler Rep 2016;18:47.
14 Paulus GF, de Vaan LE, Verdam FJ, Bouvy ND, Ambergen TA, van Heurn LW: Bariatric surgery in morbidly obese adolescents: a systematic review and meta-analysis. Obes Surg 2015;25:860-878.

15 Thongprayoon C, Cheungpasitporn W, Vijayvargiya $P$, Anthanont $P$, Erickson SB: The risk of kidney stones following bariatric surgery: a systematic review and meta-analysis. Ren Fail 2016;38:424-430.

16 Benaiges D, Más-Lorenzo A, Goday A, Ramon JM, Chillarón JJ, Pedro-Botet J, Flores-Le Roux JA: Laparoscopic sleeve gastrectomy: more than a restrictive bariatric surgery procedure? World J Gastroenterol 2015;21:11804-11814.

17 Osland E, Yunus RM, Khan S, Memon B, Memon MA: Late postoperative complications in laparoscopic sleeve gastrectomy (LVSG) versus laparoscopic Roux-en-Y gastric bypass (LRYGB): meta-analysis and systematic review. Surg Laparosc Endosc Percu$\tan$ Tech 2016;26:193-201.

18 Morais M, Faria G, Preto J, Costa-Maia J: Gallstones and bariatric surgery: to treat or not to treat? World J Surg 2016, Epub ahead of print.

19 Froylich D, Corcelles R, Davis M, Boules M, Daigle CR, Schauer PR, Brethauer SA: Factors associated with length of stay in intensive care after bariatric surgery. Surg Obes Relat Dis 2015, DOI: 10.1016/j.soard.2015.11.031.
Intestinal Inflammation and Bariatric Surgery
Inflamm Intest Dis 2016;1:129-134 DOI: $10.1159 / 000449267$ 
-20 Viana EC, Araujo-Dasilio KL, Miguel GP, Bressan J, Lemos EM, Moyses MR, de Abreu GR, de Azevedo JL, Carvalho PS, Passos-Bueno MR, Errera FI, Bissoli NS: Gastric bypass and sleeve gastrectomy: the same impact on IL-6 and TNF- $\alpha$. Prospective clinical trial. Obes Surg 2013;23:1252-1256.

21 Sams VG, Blackledge C, Wijayatunga N, Barlow P, Mancini M, Mancini G, MoustaidMoussa N: Effect of bariatric surgery on systemic and adipose tissue inflammation. Surg Endosc 2016;30:3499-3504.

22 Kelly AS, Ryder JR, Marlatt KL, Rudser KD, Jenkins T, Inge TH: Changes in inflammation, oxidative stress and adipokines following bariatric surgery among adolescents with severe obesity. Int J Obes (Lond) 2016;40: 275-280.

-23 Brethauer SA, Heneghan HM, Eldar S, Gatmaitan P, Huang H, Kashyap S, Gornik HL, Kirwan JP, Schauer PR: Early effects of gastric bypass on endothelial function, inflammation, and cardiovascular risk in obese patients. Surg Endosc 2011;25:2650-2659.

- 24 Sparks JA, Halperin F, Karlson JC, Karlson EW, Bermas BL: Impact of bariatric surgery on patients with rheumatoid arthritis. Arthritis Care Res (Hoboken) 2015;67:1619-1626.

-25 Romero-Talamás H, Aminian A, Corcelles R, Fernandez AP, Schauer PR, Brethauer S: Psoriasis improvement after bariatric surgery. Surg Obes Relat Dis 2014;10:1155-1159.

26 Yildiz BD: Rapid remission of psoriasis after sleeve gastrectomy. Indian J Surg 2016;78:6062.

27 Choi HK, Zhang Y: Bariatric surgery as uratelowering therapy in severe obesity. Ann Rheum Dis 2014;73:791-793.

-28 Corcelles R, Daigle CR, Talamas HR, Batayyah E, Brethauer SA, Schauer PR: Bariatric surgery outcomes in patients with systemic lupus erythematosus. Surg Obes Relat Dis 2015;11:684-688.

29 Boutros M, Maron D: Inflammatory bowel disease in the obese patient. Clin Colon Rectal Surg 2011;24:244-252.

30 Ferrari L, Krane MK, Fichera A: Inflammatory bowel disease surgery in the biologic era. World J Gastrointest Surg 2016;8:363-370.

- 31 Rosenthal RJ, Bashankaev B, Wexner SD: Laparoscopic management of inflammatory bowel disease. Dig Dis 2009;27:560-564.

-32 Causey MW, Johnson EK, Miller S, Martin M, Maykel J, Steele SR: The impact of obesity on outcomes following major surgery for Crohn's disease: an American College of Surgeons National Surgical Quality Improvement Program assessment. Dis Colon Rectum 2011;54:1488-1495.

33 Guardado J, Carchman E, Danicic AE, Salgado J, Watson AR, Celebrezze JP, Medich DS, Holder-Murray J: Obesity does not impact perioperative or postoperative outcomes in patients with inflammatory bowel disease. J Gastrointest Surg 2016;20:725-733.

- 34 Kato J, Hiraoka S, Nakarai A, Takashima S, Inokuchi T, Ichinose M: Fecal immunochemical test as a biomarker for inflammatory bowel diseases: can it rival fecal calprotectin? Intest Res 2016;14:5-14.

35 Koulaouzidis A, Sipponen T, Nemeth A, Makins R, Kopylov U, Nadler M, Giannakou A, Yung DE, Johansson GW, Bartzis L, Thorlacius H, Seidman EG, Eliakim R, Plevris JN, Toth E: Association between fecal calprotectin levels and small-bowel inflammation score in capsule endoscopy: a multicenter retrospective study. Dig Dis Sci 2016;61:20332040.

36 Nijhuis J, Rensen SS, Slaats Y, van Dielen FM, Buurman WA, Greve JW: Neutrophil activation in morbid obesity, chronic activation of acute inflammation. Obesity (Silver Spring) 2009;17:2014-2018.

37 Keidar A, Hazan D, Sadot E, Kashtan H, Wasserberg N: The role of bariatric surgery in morbidly obese patients with inflammatory bowel disease. Surg Obes Relat Dis 2015;11: 132-136.

38 Colombo F, Rizzi A, Ferrari C, Frontali A, Casiraghi S, Corsi F, Sampietro GM, Foschi D: Bariatric surgery in patients with inflammatory bowel disease: an accessible path? Report of a case series and review of the literature. J Crohns Colitis 2015;9:185-190.

39 Aminian A, Andalib A, Ver MR, Corcelles R, Schauer PR, Brethauer SA: Outcomes of bariatric surgery in patients with inflammatory bowel disease. Obes Surg 2016;26:1186-1190.

40 Hass DJ, Brensinger CM, Lewis JD, Lichtenstein GR: The impact of increased body mass index on the clinical course of Crohn's disease. Clin Gastroenterol Hepatol 2006;4:482488.

41 Moum B, Jahnsen J: Obesity surgery in inflammatory bowel disease. Tidsskr Nor Laegeforen 2010;130:638-639.

42 Kaplan JA, Schecter SC, Rogers SJ, Lin MY, Posselt AM, Carter JT: Expanded indications for bariatric surgery: should patients on chronic steroids be offered bariatric procedures? Surg Obes Relat Dis 2015, Epub ahead of print.

43 Lascano CA, Soto F, Carrodeguas L, Szomstein S, Rosenthal RJ, Wexner SD: Management of ulcerative colitis in the morbidly obese patient: is bariatric surgery indicated? Obes Surg 2006;16:783-786.

44 Tenorio Jiménez C, Manzano García G, Prior Sánchez I, Corpas Jiménez MS, Molina Puerta MJ, Benito López P: Bariatric surgery in inflammatory bowel disease; case report and review of the literature. Nutr Hosp 2013;28: 958-960.

45 Angrisani L, Santonicola A, Iovino P, Formisano G, Buchwald H, Scopinaro N: Bariatric
Surgery Worldwide 2013. Obes Surg 2015;25: 1822-1832.

46 Carswell KA, Vincent RP, Belgaumkar AP, Sherwood RA, Amiel SA, Patel AG, le Roux CW: The effect of bariatric surgery on intestinal absorption and transit time. Obes Surg 2014;24:796-805.

47 Ahn LB, Huang CS, Forse RA, Hess DT, Andrews C, Farraye FA: Crohn's disease after gastric bypass surgery for morbid obesity: is there an association? Inflamm Bowel Dis 2005;11:622-624.

48 Janczewska I, Nekzada Q, Kapraali M: Crohn's disease after gastric bypass surgery. BMJ Case Rep 2011, DOI: 10.1136/ bcr.07.2010.3168.

49 Kotze PG, Bremer-Nones R, Kotze LM: Is there any relation between gastric bypass for morbid obesity and the development of Crohn's disease? J Crohns Colitis 2014;8:712-713.

50 Kamiński JP, Maker VK, Maker AV: Management of patients with abdominal malignancy after remote jejunoileal bypass: surgical considerations decades later. J Am Coll Surg 2013;217:929-939.

51 Papakonstantinou AS, Stratopoulos C, Terzis I, Papadimitriou N, Spiliadi C, Katsou G, Hadjiyannakis E: Ulcerative colitis and acute stroke: two rare complications after Mason's vertical banded gastroplasty for treatment of morbid obesity. Obes Surg 1999;9:502-505.

-52 Lewis JD, Chen EZ, Baldassano RN, Otley AR, Griffiths AM, Lee D, Bittinger K, Bailey A, Friedman ES, Hoffmann C, Albenberg L, Sinha R, Compher C, Gilroy E, Nessel L, Grant A, Chehoud C, Li H, Wu GD, Bushman FD: Inflammation, antibiotics, and diet as environmental stressors of the gut microbiome in pediatric Crohn's disease. Cell Host Microbe 2015;18:489-500.

53 Palleja A, Kashani A, Allin KH, Nielsen T, Zhang C, Li Y, Brach T, Liang S, Feng Q, Jørgensen NB, Bojsen-Møller KN, Dirksen C, Burgdorf KS, Holst JJ, Madsbad S, Wang J, Pedersen O, Hansen T, Arumugam M: Rouxen-Y gastric bypass surgery of morbidly obese patients induces swift and persistent changes of the individual gut microbiota. Genome Med 2016;8:67.

54 Canales BK, Ellen J, Khan SR, Hatch M: Steatorrhea and hyperoxaluria occur after gastric bypass surgery in obese rats regardless of dietary fat or oxalate. J Urol 2013;190:11021109.

55 Michalak A, Mosińska P, Fichna J: Common links between metabolic syndrome and inflammatory bowel disease: current overview and future perspectives. Pharmacol Rep 2016; 68:837-846.

56 Gagner M, Hutchinson C, Rosenthal R: Fifth International Consensus Conference: current status of sleeve gastrectomy. Surg Obes Relat Dis 2016;12:750-756. 